\title{
Leaching characteristics and curing mechanism of magnesium phosphate cement solidified zinc-contaminated soil in an acid rain environment
}

\author{
Zhe Wang ${ }^{1}$, Hangjun Zhu ${ }^{1}$, Xuehui $\mathrm{Wu}^{1}$, Binpin Wei ${ }^{1}$, Hongli $\mathrm{Zhou}^{2}$, Sifa $\mathrm{Xu}^{{ }^{+}}$ \\ ${ }^{1}$ Institute of Geotechnical Engineering, Zhejiang University of Technology, Hangzhou 310014, China \\ ${ }^{2}$ School of Civil and Transportation, Hohai University, Nanjing 210016, China
}

\begin{abstract}
A semi-dynamic leaching test was used to simulate the erosion effect of acid rain on magnesium phosphate cement (MPC)-stabilized/solidified zinc-contaminated soil. The leaching characteristics and curing mechanism were studied with a combination of X-ray diffraction (XRD) and scanning electron microscopy (SEM). Influences of the initial $\mathrm{pH}$ value of the simulated acid rain, the ratio of the curing agent $\left(\mathrm{MgO} / \mathrm{KH}_{2} \mathrm{PO}_{4}\right.$, abbreviated $\mathrm{M} / \mathrm{P}$ ), and the mass of water glass on the leaching characteristics of $\mathrm{Zn}^{2+}$ and conductivity in the leachate of the sample were studied. It is shown that the curing effect of the cement component on $\mathrm{Zn}^{2+}$ is better for $\mathrm{M} / \mathrm{P}=6$ when compared to $\mathrm{M} / \mathrm{P}=4$ in a strong acid environment. While in a weak acid environment, it is observed that the curing effect is superior when $\mathrm{M} / \mathrm{P}=4$. Also it is observed that $4 \%$ water glass content can effectively improve the cement curing effect of heavy metal $\mathrm{Zn}$ in an acid rain environment. These results indicate that water glass can be effectively applied to MPC solidified heavy metal $\mathrm{Zn}$.
\end{abstract}

Keywords: Acid rain, Leaching characteristics, Solidified/stabilized, Water glass, Zinc contaminated soil

\section{Introduction}

In recent years, with the acceleration of urbanization, soil pollution has become increasingly severe, and soils in many countries and regions have been polluted by heavy metals to varying degrees [1-3]. Investigations have found that the zinc content accounted for a large proportion of the heavy in contaminated soil [4-6]. The heavy metal zinc poses a serious threat to groundwater bodies, human health, and the ecological environment [7], so it is necessary to treat and repair zinc-contaminated soil.

Solidification/stabilization (S/S) technology has been widely used to treat and repair heavy metal-contaminated soil due to its advantages, such as high efficiency, economy, and convenience [8-11]. Generally, the S/S method generally refers to the ordinary Portland cement S/S method.

Many scholars worldwide have conducted extensive research on the leaching characteristics of solidified heavy metal-contaminated soil [12-14]. Existing studies have shown that several factors, such as the cement materials, cement components, and curing time, can affect the leaching characteristics of contaminated soil, and reasonable cement components and prolonged cement curing time can effectively reduce the leaching behavior of heavy metals in polluted soil [11, 15, 16]. However, when the solidified contaminated soil is affected by acid rain, it affects the dissolution of the heavy metals in the solidified contaminated soil. Fu found that the leaching infiltration of acid rain causes cement hydration products to dissolve and diffuse the heavy metals solidified therein and even exceed the limit instituted by the Ministry of Environmental Protection on the concentration of the leaching in heavy metals, causing secondary pollution to the surrounding environment [17]. Du found that when cement solidified heavy metal contaminated soil, a strongly acidic leaching solution $(\mathrm{pH}=2.0)$ significantly changed the leaching behavior of the lead and calcium in the soil, but when the leaching agent was weakly acidic $(\mathrm{pH}$ $=4.0$ ) and neutral $(\mathrm{pH}=7.0)$, the difference in the soil leaching behavior was small [18]. Therefore, research on the solidification
This is an Open Access article distributed under the terms of the Creative Commons Attribution Non-Commercial License (http://creativecommons.org/licenses/by-nc/3.0/) which permits unrestricted non-commercial use, distribution, and reproduction in any medium, provided the original work is properly cited.

Copyright (C) 2021 Korean Society of Environmental Engineers
Received May 21, 2020 Accepted August 21, 2020

${ }^{\dagger}$ Corresponding author

E-mail: xusifa@zjut.edu.cn

Tel: + 1-358-800-2752

ORCID: 0000-0002-7558-3146 
mechanism and heavy metal leaching mechanism of solidified heavy metal-contaminated soil in an acid rain environment is of great scientific significance to improve the acid resistance of solidified contaminated soil.

There is also increasing research on the use of magnesium phosphate cement (MPC) for curing radioactive and hazardous wastes. Rao showed that magnesium phosphate cement is widely used to solidify contaminated soils because the solubility of heavy metals in phosphate is very low [19]. Buj used potassium magnesium phosphate cement (MKPC) to solidify contaminated soil and obtained improved curing results in acidic and neutral environments [20]. Li and Arora found that magnesium phosphate cement has a better curing effect on pollutants than that of ordinary cement, and the effect of reducing the solubility of pollutants in solidified contaminated soil is achieved by generating poorly soluble alkaline hydrates or solidifying them in the hydrate lattice [21-22]. Although much research has been carried out on the solidification of magnesium phosphate cement-contaminated soil, there is little research on the acid resistance of magnesium phosphate cement-contaminated soil under acid rain. $\mathrm{Xu}$ found that the total amount of leaching of zinc ions significantly increases when magnesium phosphate cement-cured zinc-contaminated soil is affected by acid rain [23]. Therefore, to effectively prevent the impact of the acid rain environment on solidified heavy metal-contaminated soil and improve the acid resistance of solidified contaminated soil, it is necessary to find suitable additives and evaluate whether the additives can effectively consolidate and stabilize heavy metals in acidic environments.

Most acid-resistant cements worldwide are prepared by adding water glass according to a certain proportion. Studies have shown that water glass has good acid resistance and high adhesion [24]. Microscopic analysis of the mechanism of water glass on MPCs found that the addition of water glass to MPCs can accelerate the early hydration of the MPC, which can decrease the size of the grains of hydrated products in the MPC hardened body, improve the structural compactness, and reduce the dissolution of the hydrated products [25-26]. However, whether the long-term properties and acid resistance of solidified heavy metal-contaminated soil can be maintained under the combined effects of acid rain and heavy metals needs further research.

In this paper, the effect of the initial $\mathrm{pH}$ value of simulated acid rain, ratio of the curing agent, and mass of water glass on the leaching characteristics of $\mathrm{Zn}^{2+}$, such as the concentration, $\mathrm{pH}$ value, and conductivity in the sample leachate, are studied and analyzed through semi-dynamic leaching tests. X-ray diffraction (XRD) is used to study the effect of water glass content on the hydration process and hydration products of heavy metal Zn solidified by magnesium phosphate cement. Scanning electron microscopy (SEM) is used to qualitatively analyze the mineral phase and microstructure characteristics of the magnesium phosphate cement-cured zinc-contaminated soil under an acid rain erosion environment. These results provide a reasonable basis for improving the selection of the solidifying agent and amount of water glass for treating soil pollution of heavy metal zinc in the future.

\section{Sample Preparation and Test Methods}

\subsection{Experimental Materials}

The soil used in the test was soft kaolin, which was produced by Lingshou County Zeshun Mineral Products Trading Co., Ltd. in Lingshou County, Hebei Province, China. The basic physical properties and mineral composition of kaolin are shown in Table 1.

The test used magnesium phosphate cement (MPC) as the curing agent. It was prepared in the laboratory by adding an appropriate amount of water according to a certain proportion from over-fired magnesium oxide $(\mathrm{MgO}$, abbreviated $\mathrm{M}$, with a specific surface area of $\left.235 \mathrm{~m}^{2} / / \mathrm{kg}\right)$, potassium dihydrogen phosphate $\left(\mathrm{KH}_{2} \mathrm{PO}_{4}\right.$, abbreviated $\mathrm{K}$ ), borax $\left(\mathrm{Na}_{2} \mathrm{~B}_{4} \mathrm{O}_{7} \cdot 10 \mathrm{H}_{2} \mathrm{O}\right.$, abbreviated $\left.\mathrm{B}\right)$, and fly ash, for example. Among them, over-fired $\mathrm{MgO}$ was produced by the Yongxiang Mineral Powder Factory. $\mathrm{KH}_{2} \mathrm{PO}_{4}$ was analytically pure and produced by Hushen Chemical Reagent Co., Ltd. The borax retarder was analytically pure and produced by Taicang Meida Reagent Co., Ltd. For the preparation of the magnesium phosphate cement, the addition amount of the borax retarder was based on the mass of the over-fired $\mathrm{MgO}$, and the addition amount was $5 \%$. In this test, different components, namely, $\mathrm{KH}_{2} \mathrm{PO}_{4}$ and over-fired $\mathrm{MgO}$, were used, and two ratios of magnesium phosphate cement were used, namely $\mathrm{M}: \mathrm{P}=4: 1$ and $\mathrm{M}: \mathrm{P}=6: 1$ (abbreviated as M4 or M6, respectively).

According to the current research of heavy metal polluted soil, zinc ( $\mathrm{Zn})$ was selected as the single heavy metal pollutant for research. The main anion in the acid rain was considered to be composed of $\mathrm{SO}_{4}{ }^{2-}$ and $\mathrm{NO}_{3}^{-}$, and the acid rain was formulated with concentrated sulfuric acid, concentrated nitric acid and deionized water by using the step dilution method. The concentration ratio of the concentrated sulfuric acid and concentrated nitric acid was 5:1, which was diluted with deionized water to a $\mathrm{pH}$ of 2 , 4 , and 7 to formulate the simulated acid rain. Because zinc nitrate has high solubility (high cationic activity) and ordinary cement hydration reactions are not as affected by the nitrate [27], the influence of different heavy metal salts on the strength of the cement does not have to be considered, so compounds with a purity grade of analytical purity (such as $\mathrm{Zn}\left(\mathrm{NO}_{3}\right)_{2} \cdot 6 \mathrm{H}_{2} \mathrm{O}$ ) were selected.

The water glass used in the test was sodium water glass $\left(\mathrm{Na}_{2} \mathrm{SiO}_{3}\right.$. $9 \mathrm{H}_{2} \mathrm{O}$ ) provided by Shanghai Culture Chemical Pigment Co., Ltd. Studies have shown that sodium water glass has good flame resistance, strong acid resistance, environmental friendliness, nontoxicity, simple processing and a low cost. The disadvantages are low adhesion, poor water resistance, and high-temperature resistance [24].

Table 1. Basic Chemical Composition of Kaolin

\begin{tabular}{lccccccccc}
\hline Index & $\mathrm{SiO}_{2}$ & $\mathrm{Al}_{2} \mathrm{O}_{3}$ & $\mathrm{Fe}_{2} \mathrm{O}_{3}$ & $\mathrm{CaO}$ & $\mathrm{MgO}$ & $\mathrm{TiO}$ & $\mathrm{K} 2 \mathrm{O}$ & $\mathrm{Na}_{2} \mathrm{O}$ & Loss on ignition \\
\hline Content & 47.86 & 38.26 & 0.06 & 0.19 & 0.08 & 0.13 & 0.04 & 0.05 & 13.65 \\
\hline
\end{tabular}




\subsection{Sample Preparation}

First, the kaolin, cement and other dry materials were mixed in proportion (the cement was magnesium phosphate cement and $\mathrm{M}=4$ or 6 ). According to the soil design, a certain amount of deionized water was added, and a magnetic stirrer was used to fully dissolve the metal nitrate solution in the deionized water to obtain a metal nitrate solution (the heavy metal content was 0 and $0.5 \%$ relative to the dry soil weight). The nitrate solution and sodium water glass modifier were added to the dry material and mixed with a blender until uniform (the content of water glass modifier was $0,2 \%$, and $4 \%$ relative to the mass of the dry soil). Subsequently, a certain amount of soil sample was weighed (according to the debugging and the estimated mass of the concrete), and after mixing well, it was filled into a mold with a diameter of $39 \mathrm{~mm}$ and a height of $80 \mathrm{~mm}$ in 3 layers according to the requirements of the geotechnical test specification. After the sample was left for $1 \mathrm{~h}$, it was demolded, weighed, and packed with plastic film to prevent any moisture loss. It was placed in a standard curing room for curing (temperature was $20 \pm 2^{\circ} \mathrm{C}$ and relative humidity was $95 \pm 3 \%$ ). The curing age was 28 days, and three parallel samples were made for each group.

The content of added heavy metals was based on the literature [28] that surveyed the pollution of industrial sites in Chinese cities. The average $\mathrm{Zn}$ concentration in the topsoil ranged from 1,189 to $16,478 \mathrm{mg} / \mathrm{kg}$, and the moisture content of the samples was $20 \%$ (relative to the dry soil + cement content).

\subsection{Test Methods}

The test in this paper was based on ASTM C1308-08 [29]. The extractant was added to a simulated acid rain solution with $\mathrm{pH}$ $=2$ and 4 based on the original standard $(\mathrm{pH}=7)$. For different initial $\mathrm{pH}$ values, three parallel experiments were performed. The test used a soil sample surface area-to-extractant volume ratio of $1: 9\left(\mathrm{~cm}^{2} / \mathrm{mL}\right)$, which was $0.11 \mathrm{~cm}^{-1}$, a single sample surface area of approximately $122 \mathrm{~cm}^{2}$, and an extractant volume of $1,100 \mathrm{~mL}$

The specific steps were as follows. First, a glass beaker was cleaned with acid, the impurities in the glass beaker were rinsed with deionized water, the prepared $\mathrm{pH}$ acid rain was poured into a beaker, and the initial extractant $\mathrm{pH}$ and temperature in the beaker were measured. After placing the standard contaminated zinc contaminated soil sample that was cured for $28 \mathrm{~d}$ on a pervious stone $(\Phi 80 \mathrm{~mm})$ at the bottom of the beaker, the time was started, and the beaker was sealed to prevent the $\mathrm{CO}_{2}$ of the air from acidifying the extractant. The extractant was renewed at intervals of $2 \mathrm{~h}, 5 \mathrm{~h}, 17 \mathrm{~h}, 24 \mathrm{~h}, 24 \mathrm{~h}, 24 \mathrm{~h}, 48 \mathrm{~h}$, and $96 \mathrm{~h}$, and the leachate was renewed 8 times for 10 days. After each sampling update, the $\mathrm{pH}$, temperature, and conductivity of the filtrate were measured, and the sample was digested with nitric acid to make up the volume to measure the $\mathrm{Zn}^{2+}$ concentration. XRD and SEM were used to analyze the solidification mechanism of Zn-contaminated soil with magnesium phosphate cement and the leaching mechanism of the $\mathrm{Zn}^{2+}$.

According to the $\mathrm{Zn}^{2+}$ concentration data measured at each leaching interval, the mass of $\mathrm{Zn}^{2+}$ dissolved on the surface of the sample was estimated by the following formula [30]:

$$
\mathrm{C}_{\mathrm{Zn}, \mathrm{i}}=\frac{\mathrm{c}_{\mathrm{Zn}, \mathrm{i}} \cdot \mathrm{V}_{\mathrm{L}, \mathrm{i}}}{\mathrm{A}_{\mathrm{s}}}
$$

In the formula, $\mathrm{C}_{\mathrm{Zn}, \mathrm{i}}$ represents the dissolution amount of $\mathrm{Zn}^{2+}$ on the sample surface after the i-th leaching $\left(\mathrm{mg} / \mathrm{cm}^{2}\right) ; \mathrm{c}_{\mathrm{Zn}, \mathrm{i}}$ represents the $\mathrm{Zn}^{2+}$ concentration (mg / L) in the leachate after the i-th leaching; $\mathrm{V}_{\mathrm{L}, \mathrm{i}}$ is the total volume $(\mathrm{L})$ of leachate after the $\mathrm{i}$-th leaching, calculated according to $1.1 \mathrm{~L}$; and $\mathrm{A}_{\mathrm{S}}$ is the contact area between the sample and the leachate $\left(\mathrm{cm}^{2}\right)$, and it is calculated to be $122 \mathrm{~cm}^{2}$. When the leaching is continuously updated, the total amount of $\mathrm{Zn}^{2+}$ dissolved can be calculated by superposing the mass of $\mathrm{Zn}^{2+}$ dissolved in each leachate at each stage:

$$
\mathrm{C}_{\mathrm{Zn}}=\sum_{\mathrm{i}=1}^{\mathrm{N}} \mathrm{C}_{\mathrm{Zn}, \mathrm{i}}
$$

\section{Results and Analysis}

\subsection{Effect of Different Water Glass Contents on the Leaching Characteristics of Solidified Zinc-Contaminated Soil}

The test abbreviated each component as MiZnj(k) ( $\mathrm{i}=\mathrm{M} / \mathrm{P}$; $\mathrm{j}$ is heavy mental content; $\mathrm{k}$ is water glass content). According to the trend for the $\mathrm{Zn}^{2+}$ concentration with leaching time in the semi-dynamic leaching test shown in Fig. 1, during leaching at $\mathrm{pH}=$ 2 , when the water glass content is $0 \%$, the leaching solution from the M4Zn0.5 and M6Zn0.5 samples has a consistent trend for $\mathrm{Zn}^{2+}$ concentration over time, all of which decrease first, then increase, and then decrease significantly, but the $\mathrm{Zn}^{2+}$ concentration of the M4Zn0.5 sample at the initial stage of leaching $(2 \sim 7 \mathrm{~h})$ is much higher than that of M6Zn0.5. Upon comparing the leaching $\mathrm{Zn}^{2+}$ concentration of the M4Zn0.5 and M6Zn0.5 samples with different water glass contents, it is found that when the water glass content is $4 \%$, the leaching $\mathrm{Zn}^{2+}$ concentration is the lowest herein. Comparing the M6Zn0.5 and M4Zn0.5 Zn ${ }^{2+}$ concentrations in the sample leaching solution with different water glass contents, it is found that M6Zn0.5 has a better zinc curing effect than M4Zn0.5.

At $\mathrm{pH}=4,7$ leaching, when the content of water glass is $0 \%$, the dissolution of the $\mathrm{Zn}^{2+}$ concentration in the M4Zn0.5 sample is greater than that in the M6Zn0.5 sample, but the trend for the two after $96 \mathrm{~h}$ of leaching accumulation are basically the same, and the concentration difference is relatively small. Upon adding different doses of water glass to the M4Zn0.5 and M6Zn0.5 samples, it can be seen that when the content of the water glass is $4 \%$, the concentration of $\mathrm{Zn}^{2+}$ leached from the sample is the lowest herein, indicating that the addition of water glass enhances the curing effect of cement on heavy metal $\mathrm{Zn}$.

Fig. S1 shows a line chart of the leaching concentration of Ding [31] solidified zinc contaminated soil. Compared with this test, the difference is mainly in the difference of the test soil (this test uses kaolin, Ding uses standard sand), the type of curing agent and Is there any water glass added. By comparing the test results of the two, it is found that under the same leaching conditions, kaolin can better cure $\mathrm{Zn}^{2+}$ by MPC than standard sand; Comparing the leaching concentration of the solidified zinc contaminated soil under different experimental materials, it is found that the addition of water glass can reduce the $\mathrm{Zn}^{2+}$ leaching concentration of the 

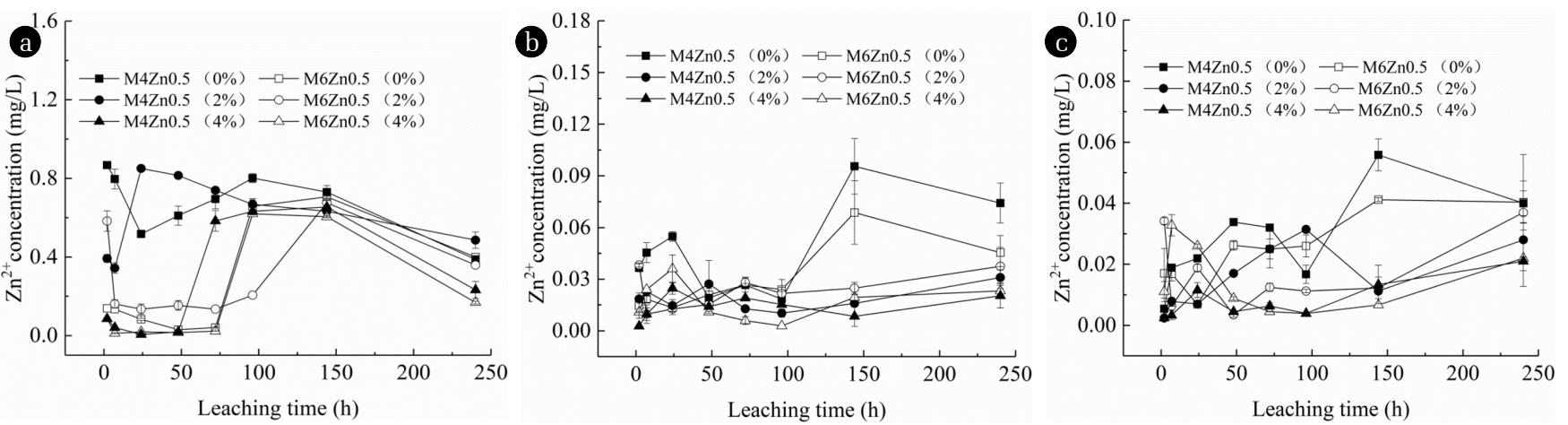

Fig. 1. Variation in $\mathrm{Zn}^{2+}$ concentration with leaching time during semi-dynamic leaching test. (a) Initial $\mathrm{pH}=2$, (b) $\mathrm{Initial} \mathrm{pH}=4$, (c) Initial $\mathrm{pH}=7$.

solidified zinc contaminated soil of MPC. Comparing the leaching concentration of $\mathrm{Zn}^{2+}$ of solidified contaminated soil, it is found that MPC has better curing effect than ordinary Portland cement; Comparing the leaching concentration of the solidified zinc contaminated soil under different experimental materials, it is found that the addition of water glass can reduce the $\mathrm{Zn}^{2+}$ leaching concentration of the solidified zinc contaminated soil of MPC.

\subsection{Effect of Different Water Glass Contents on the Total Leaching of Solidified Zinc-Contaminated Soil}

The total amount of $\mathrm{Zn}^{2+}$ dissolved on the surface of the sample calculated by the above formula (2) is shown in Fig. 2. Comparing the total dissolution of heavy metal $\mathrm{Zn}^{2+}$ in the solidified zinc-contaminated soil at different $\mathrm{pH}$ values, it can be found that the total amount of $\mathrm{Zn}^{2+}$ dissolved on the surface of the sample when the initial $\mathrm{pH}=2$ during the semi-dynamic leaching test that simulates acid rain is generally higher than that when the $\mathrm{pH}$ $=4$ and 7 . The total amount of $\mathrm{Zn}^{2+}$ eluted from the surface of M4Zn0.5(0\%) at $\mathrm{pH}=2$ is 14 times and 27.8 times that at $\mathrm{pH}$ $=4$ and 7 , respectively, and the total amount of $\mathrm{Zn}^{2+}$ dissolved on the sample surface of M6Zn0.5(0\%) at $\mathrm{pH}=2$ is 9.9 times and 11.6 times that at $\mathrm{pH}=4$ and 7 , respectively, indicating that a strong acid environment greatly disrupts the curing effect of magnesium phosphate cement on zinc contaminated soil.

When the initial $\mathrm{pH}$ of the simulated acid rain is 2 , the total amount of $\mathrm{Zn}^{2+}$ dissolved in the M4Zn0.5 and M6Zn0.5 samples at different water glass contents $(0 \%, 2 \%$, and $4 \%)$ is analyzed. When the content of water glass is $4 \%$, the total amount of $\mathrm{Zn}^{2+}$ leached from the sample is the lowest among the water glass contents, indicating that the $4 \%$ water glass content has the best curing effect on the magnesium phosphate cement-cured zinc-contaminated soil.

The total amount of $\mathrm{Zn}^{2+}$ dissolved on the surface of the M4Zn0.5 sample compared with that on the surface of the M6Zn0.5 sample shows that when the content of the water glass is $0 \%, 2 \%$, and $4 \%$, the total amount of $\mathrm{Zn}^{2+}$ dissolved on the surface of the M4Zn0.5 sample is always higher than the total amount of $\mathrm{Zn}^{2+}$ dissolved on the surface of the M6Zn0.5 sample.

When the initial $\mathrm{pH}$ value of the simulated acid rain is 4 , the total dissolved $\mathrm{Zn}^{2+}$ on the surface of the M4Zn0.5(0\%) sample is 2.6 times and 3.4 times that of the M4Zn0.5(2\%) and M4Zn0.5(4\%) samples, respectively, and the total amount of $\mathrm{Zn}^{2+}$ dissolved on the surface of the M6Zn0.5(0\%) sample is 1.46 times and 1.96 times that of the M6Zn0.5(2\%) and M6Zn0.5(4\%) samples, respectively. When the content of water glass is $0 \%$, the total amount of $\mathrm{Zn}^{2+}$ dissolved on the surface of the M6Zn0.5 sample is less than that of the M4Zn0.5 sample. When the content of water glass is $2 \%$ and $4 \%$, the total amount of $\mathrm{Zn}^{2+}$ dissolved on the surface of the M6Zn0.5 sample is greater than that of the M4Zn0.5 sample, indicating that when water glass is added in a weak acid environ-
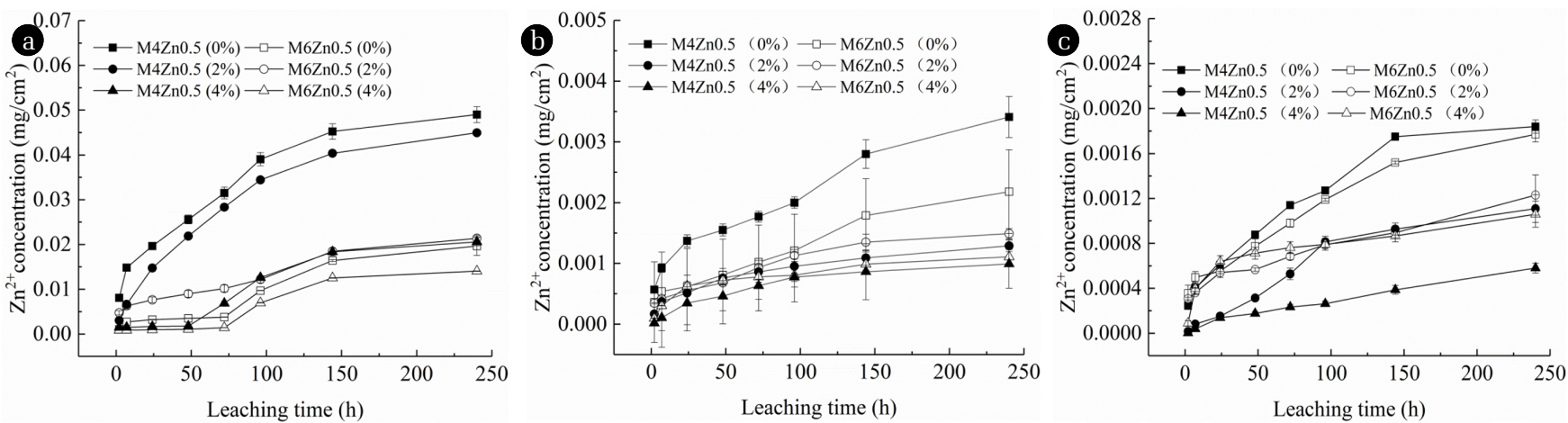

Fig. 2. Total dissolved $\mathrm{Zn}^{2+}$ on the surface of the solidified zinc-contaminated soil sample. (a) Initial $\mathrm{pH}=2$, (b) Initial $\mathrm{pH}=4$, (c) Initial $\mathrm{pH}=7$. 
ment, the curing effect of M4 on zinc is better than that of M6.

In a neutral environment with an initial $\mathrm{pH}=7$, the total amount of $\mathrm{Zn}^{2+}$ dissolved on the surface of the M4Zn0.5(0\%) sample is 1.6 and 3 times that of the M4Zn0.5(2\%) and M4Zn0.5(4\%) samples, respectively, and the total amount of $\mathrm{Zn}^{2+}$ dissolved on the surface of the M6Zn0.5(0\%) sample is 1.44 times and 1.67 times that of the M6Zn0.5(2\%) and M6Zn0.5(4\%) samples, respectively. The total amount of $\mathrm{Zn}^{2+}$ dissolved on the surface of the sample with $\mathrm{M}=4$ is always lower than that on the surface of the sample with $\mathrm{M}=6$.

Comparing the test results with the figure of total dissolution of Zn ions in Ding [31] solidified zinc contaminated soil in Fig. $\mathrm{S} 2$, it is found that kaolin can better cure $\mathrm{Zn}^{2+}$ of MPC than standard sand under the same leaching environment. This is because kaolin has a large specific surface area and good adsorption performance, and can play a certain role in adsorbing heavy metal ions; Compared with the total amount of $\mathrm{Zn}^{2+}$ leaching of the solidified contaminated soil, it is found that the total amount of $\mathrm{Zn}^{2+}$ leached by the ordinary Portland cement solidified zinc contaminated soil at the end of the leaching is greater than the total amount of $\mathrm{Zn}^{2+}$ leached by the MPC solidified zinc contaminated soil, indicating that MPC has better curing effect than ordinary Portland cement. The addition of water glass can reduce the total amount of $\mathrm{Zn}$ leaching of solidified zinc contaminated soil, especially $4 \%$ water glass greatly improves the curing effect of cement solidified soil on heavy metal zinc.

\section{3. $\mathrm{pH}$ and Conductivity of the Leaching Supernatant of the Solidified Zinc-Contaminated Soil}

Fig. 3 shows the change in the $\mathrm{pH}$ of the leaching supernatant with leaching time when the initial $\mathrm{pH}$ of the acid rain is 4 . The study finds that the $\mathrm{pH}$ range of the leaching supernatant of the updated leaching group is $5.0 \sim 10.8$ when the initial $\mathrm{pH}$ value of the simulated acid rain is 4 . At the same time, when the initial $\mathrm{pH}$ of the simulated acid rain is 4, the excess $\mathrm{OH}^{-}$in the solidification system is ionized, and $\mathrm{H}^{+}$in the acid solution remains after neutralization so that the leaching solution becomes alkaline. It can also be seen from Fig. 3 that in each group of samples, the $\mathrm{pH}$ of the leaching solution of the solidified soil from the M6 group is generally higher than that of the M4 group. The abovementioned $\mathrm{pH}$ trend is basically consistent with the analysis results of the $\mathrm{Zn}^{2+}$ concentration law in the leaching solution and the $\mathrm{Zn}^{2+}$ diffusion mechanism. This is consistent with the results of the study by Wang on the change in the $\mathrm{pH}$ and leaching characteristics of $\mathrm{Zn}^{2+}$, so the leaching characteristics of $\mathrm{Zn}^{2+}$ in the semi-dynamic leaching test can be confirmed again by the change in the $\mathrm{pH}$ of the leaching supernatant [32].

In this leaching test, the conductivity of the leaching solution of the sample in each updated leaching phase was tested, and the conductivity of the samples in the updated leaching group was cumulatively compared. As shown in Fig. 4, the conductivity of the leaching supernatant varies with the leaching time. The research finds that when the initial $\mathrm{pH}$ value of the simulated acid rain is 4 , the conductivity trend is not much different. After the leaching accumulation time reaches $144 \mathrm{~h}$, it is in a "dynamic equilibrium" state. The so-called "dynamic equilibrium" refers to the use of simulated acid rain to continuously replace the leachate

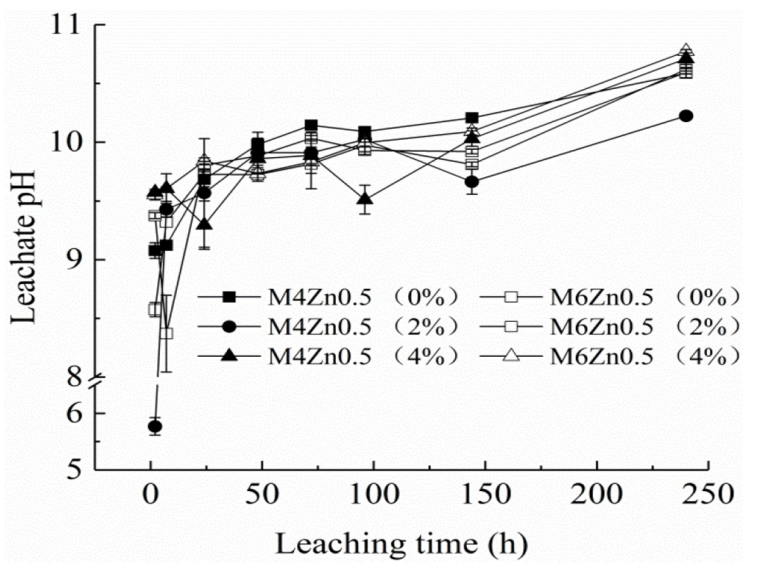

Fig. 3. Change in the $\mathrm{pH}$ of the leaching supernatant with leaching time.

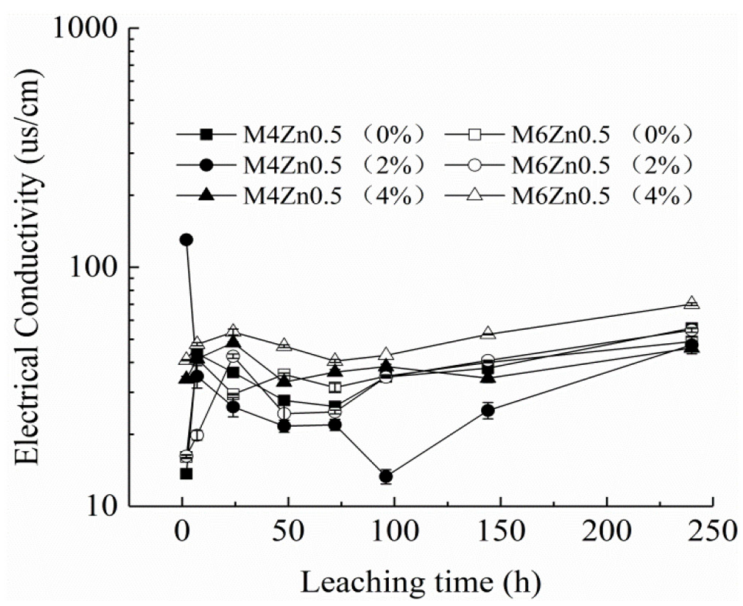

Fig. 4. Changes in the conductivity of leaching supernatant with leaching time. (Initial $\mathrm{pH}=4$ )

to extract heavy metals from the solidified soil in a semi-dynamic leaching experiment after a certain period of time. The total amount of ions in the leachate after leaching in the curing system reached a stable state, and the ionized ions are mainly $\mathrm{OH}^{-}$ions; thus, the macroscopic performance of this state is that the conductivity of the leachate is stable after the cumulative leaching time reaches $144 \mathrm{~h}$.

\subsection{Reaction Mechanism of the MPC Cured Zinc Contaminated Soil}

Fig. 5 and Fig. 6 show the XRD diffraction patterns of the M6Zn0.5(0\%) samples and M6Zn0.5(4\%) samples after semi-dynamic leaching, respectively, at the initial $\mathrm{pH}=2,4$, and 7 of the simulated acid rain and after standard curing for 38 days. According to Fig. 5 and 6 , it can be seen that the XRD patterns of the semi-dynamic leached sample M6Zn0.5(0\%) and M6Zn0.5(4\%) indicate the presence of $\mathrm{KMgPO}_{4} \cdot 6 \mathrm{H}_{2} \mathrm{O}$ (MKP), $\mathrm{Mg}_{3}$ $\left(\mathrm{PO}_{4}\right)_{2} \cdot 22 \mathrm{H}_{2} \mathrm{O}, \mathrm{Mg}_{3}\left(\mathrm{PO}_{4}\right)_{2} \cdot 8 \mathrm{H}_{2} \mathrm{O}$ and other major cement hydration products. This is because the reaction mechanism of magnesium phosphate cement is based on the acid-base reaction of sparingly soluble salts. After MPC powder is mixed with water, potassium 
dihydrogen phosphate is dissolved and ionized to generate $\mathrm{K}^{+}$, $\mathrm{H}^{+}$and $\mathrm{Mg}^{2+}$. After the magnesium oxide powder encounters water and $\mathrm{H}^{+}$, the surface of the particles is dissolved to form $\mathrm{Mg}^{2+}$ and $\mathrm{OH}^{-}$, and $\mathrm{H}^{+}$reacts with $\mathrm{OH}^{-}$to release a large amount of heat, and the acid-base neutralization reaction accelerates the dissolution of potassium dihydrogen phosphate and magnesium oxide. Free $\mathrm{Mg}^{2+}$ interacts with $\mathrm{K}^{+}$and $\mathrm{H}^{+}$to form hydrated gel $\mathrm{MgKPO}_{4}$ - $6 \mathrm{H}_{2} \mathrm{O}$ and other gel substances, among which $\mathrm{MgKPO}_{4} \cdot 6 \mathrm{H}_{2} \mathrm{O}$ is the main reaction product. As the reaction progresses, white crystals precipitate on the surface of the test block, and the main components of the surface leaching process are $\mathrm{MgKPO}_{4} \cdot 6 \mathrm{H}_{2} \mathrm{O}$ and a small amount of $\mathrm{K}_{2} \mathrm{HPO}_{4}$ crystals. [33-38]. The ionization equation during hydration includes the ionization process of $\mathrm{KH}_{2} \mathrm{PO}_{4}$, the hydrolysis of magnesium oxide, and the formation of $\mathrm{MgKPO}_{4} \cdot 6 \mathrm{H}_{2} \mathrm{O}$ [39-41].

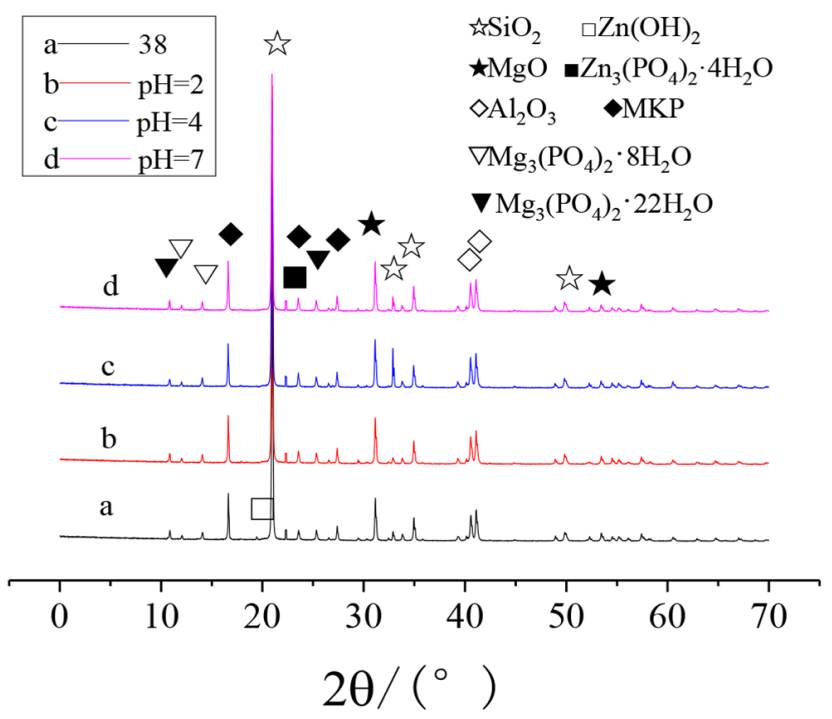

Fig. 5. XRD pattern of the semi-dynamic leached M6Zn0.5(0\%) samples.

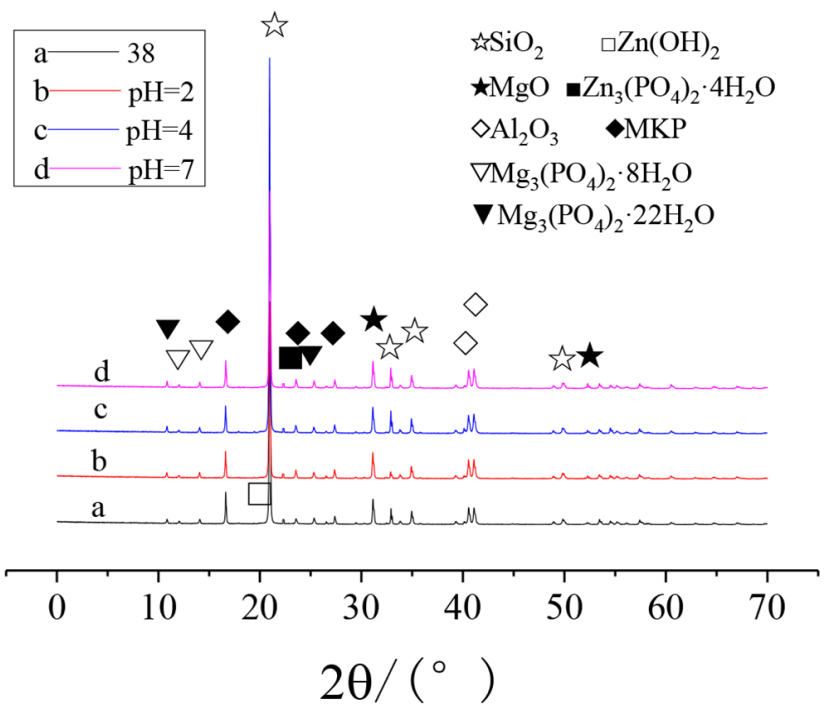

Fig. 6. XRD pattern of semi-dynamic leached M6Zn0.5(4\%) samples.
It can also be found on the spectrum that the strong diffraction peaks are mainly from $\mathrm{SiO}_{2}$, MKP formed by the reaction, and unreacted $\mathrm{MgO}$ and $\mathrm{Al}_{2} \mathrm{O}_{3}$. In addition, $\mathrm{Zn}_{3}\left(\mathrm{PO}_{4}\right)_{2} \cdot 4 \mathrm{H} 2 \mathrm{O}$ and $\mathrm{Zn}(\mathrm{OH})_{2}$ are also detected in the M6Zn0.5(0\%) and M6Zn0.5(4\%) samples. Among them, $\mathrm{Zn}(\mathrm{OH})_{2}$ is only detected in the sample with standard curing for 38 days, and $\mathrm{Zn}_{3}\left(\mathrm{PO}_{4}\right)_{2} \cdot 4 \mathrm{H}_{2} \mathrm{O}$ is detected in the environment with $\mathrm{pH}=2,4$, and 7 and standard curing for 38 days. This is because $\mathrm{Zn}$ is an amphoteric metal that can generate phosphates (such as $\mathrm{Zn}_{3}\left(\mathrm{PO}_{4}\right)_{2} \cdot 4 \mathrm{H}_{2} \mathrm{O}$ ) with the acid ion ionized by $\mathrm{KH}_{2} \mathrm{PO}_{4}$, and it can generate a $\mathrm{Zn}(\mathrm{OH})_{2}$ amphoteric hydroxide with $\mathrm{OH}^{-}$ions generated by the hydrolysis of $\mathrm{MgO}$. $\mathrm{Zn}_{3}\left(\mathrm{PO}_{4}\right)_{2} \cdot 4 \mathrm{H}_{2} \mathrm{O}$ appears under simulated acid rain at $\mathrm{pH}=2$, 4 , and 7 and the standard curing environment, while $\mathrm{Zn}(\mathrm{OH})_{2}$ only appears in the sample after standard curing for 38 days, which is due to $\mathrm{Zn}_{3}\left(\mathrm{PO}_{4}\right)_{2} \cdot 4 \mathrm{H}_{2} \mathrm{O}$ being generated when the solution $\mathrm{pH}=3 \sim 7 . \mathrm{Zn}(\mathrm{OH})_{2}$ needs to be greater than 8 to generate, which is consistent with the microscopic research on magnesium phosphate cement solidified heavy metal zinc $[20,42]$. Its chemical reaction equation is:

$$
\begin{gathered}
3 \mathrm{Zn}^{2+}+2 \mathrm{PO}_{4}{ }^{3-}+4 \mathrm{H}_{2} \mathrm{O} \leftrightarrow \mathrm{Zn}_{3}\left(\mathrm{PO}_{4}\right)_{2} \bullet 4 \mathrm{H}_{2} \mathrm{O} \\
(\text { Phosphate, } \mathrm{pH}=3 \sim 7) \\
\mathrm{Zn}^{2+}+2 \mathrm{OH}^{-} \leftrightarrow \mathrm{Zn}(\mathrm{OH})_{2} \\
\text { (Hydroxide, } \mathrm{pH}=8 \sim 14)
\end{gathered}
$$

When simulating the effect of the initial $\mathrm{pH}$ of acid rain at $\mathrm{pH}=2,4$, and 7 , the peak value of the MKP is lower than that after the 38 days standard curing, indicating that the amount of generated MKP is reduced, which can explain why many water and acidic environments can cause dissolution of MKP. The peak intensity corresponding to MKP is the lowest herein when the initial $\mathrm{pH}=2$. This is because a large amount of $\mathrm{H}^{+}$promotes the reverse reaction of MKP so that it dissolves into $\mathrm{Mg}^{2+}, \mathrm{K}^{+}$, $\mathrm{PO}_{4}{ }^{3-}$. As the main product of the hydration reaction of MPC cement, MKP transforms into other more stable phases with changes in external water content and $\mathrm{pH}$ value, but under acidic conditions, MKP dissolves.

The main body of the sodium water glass adhesive is colloidal silicon dioxide, which is hydrolyzed into silicic acid in aqueous solution and interacts with carbon dioxide in the air. The silicic acid that is formed is gradually dried and solidified, finally forming a bonded network structure [24, 43]:

$$
\begin{gathered}
\mathrm{Na}_{2} \mathrm{O} \bullet \mathrm{nSiO}_{2}+(2 n+1) \mathrm{H}_{2} \mathrm{O} \rightarrow 2 \mathrm{NaOH}+\mathrm{nSi}(\mathrm{OH})_{4} \\
\mathrm{Na}_{2} \mathrm{O} \bullet \mathrm{nSiO}_{2}+2 \mathrm{nH}_{2} \mathrm{O}+\mathrm{CO}_{2} \rightarrow \mathrm{NaCO}_{3}+\mathrm{nSi}(\mathrm{OH})_{4} \\
\mathrm{nSi}(\mathrm{OH})_{4} \stackrel{\text { polycondensation }}{\longrightarrow}\left[\mathrm{Si}(\mathrm{OH})_{4}\right] n \stackrel{\text { Dehydration }}{\longrightarrow} \mathrm{nSiO}_{2}
\end{gathered}
$$

It can be found on the spectrum that the peak of $\mathrm{Mg}_{3}\left(\mathrm{PO}_{4}\right)_{2} \cdot 22 \mathrm{H}_{2} \mathrm{O}$ increases after adding water glass, which and it also promotes the generation of $\mathrm{Mg}_{3}\left(\mathrm{PO}_{4}\right)_{2} \cdot 8 \mathrm{H}_{2} \mathrm{O}$. This is because the addition of water glass can prevent MKP from dissolving again, and in a large amount of aqueous solution, MKP will tend to be converted into the more stable compound $\mathrm{Mg}_{3}\left(\mathrm{PO}_{4}\right)_{2} \bullet 22 \mathrm{H}_{2} \mathrm{O}$, which is a slower 
conversion process, and then $\mathrm{Mg}_{3}\left(\mathrm{PO}_{4) 2} \cdot 22 \mathrm{H}_{2} \mathrm{O}\right.$ turns into the most stable gel $\mathrm{Mg}_{3}\left(\mathrm{PO}_{4}\right)_{2} \bullet 8 \mathrm{H}_{2} \mathrm{O}$ under weak alkaline environment; After adding water glass, some of the $\mathrm{SiO}_{2}$ peaks are higher after the standard curing for 38 days and in the acidic environment than in the weak acid environment, indicating that a certain acidic environment promotes the condensation of $\mathrm{Si}(\mathrm{OH})_{4}$ to form $\mathrm{SiO}_{2}$. The reason that $\mathrm{Si}(\mathrm{OH})_{4}$ is not detected in this test may be that, on the one hand, $\mathrm{Si}(\mathrm{OH})_{4}$ exists for a relatively short amount of time.

\subsection{Microstructure Analysis of MPC Solidified Zinc Contaminated Soil}

In this paper, a HITACHI S-4700 scanning electron microscope was used to scan the sample after the semi-dynamic leaching test. To determine the effect of the water glass content and heavy metal content on the effect of magnesium phosphate cement solidified zinc contaminated soil, the M6Zn0(0\%), M6Zn0.5(0\%), and M6Zn0.5(4\%) samples were subjected to an environment of simulated acid rain at $\mathrm{pH}=4$. The microscopic image of MPC-cured zinc-contaminated soil is shown in Fig. 7.

Upon observing the microstructure of the sample with initial acid rain $\mathrm{pH}=4$, it can be seen that compared with the $\mathrm{M} 6 \mathrm{ZnO}(0 \%)$ sample that did not contain heavy metals, the M6Zn0.5(0\%) sample has a large number of coarse holes, broken crystals, and lack of water between the particles. The close connection of the gel product results in a decrease in overall compactness, which is caused by $\mathrm{Zn}^{2+}$ inhibiting the partial production of MKP. At the same time, the cementation between the soil particles and the gel is reduced, resulting in an increase in the structural dispersion of the solidified soil, decreasing the sample structure strength, and increasing the dissolution probability of $\mathrm{Zn}^{2+}$. This is similar to the research results of Lai Z. Y and He Y. J, which show that heavy metal ions reduce the cementation between soil particles and gels, leading to an increase in the structural dispersion of the solidified soil and increasing the probability of the dissolution of heavy metal ions [44, 45].

Compared with the M6Zn0.5(0\%) sample without water glass, the M6Zn0.5(4\%) sample reduces the porosity between the particles and increases the compactness of the sample structure This is consistent with the XRD analysis results for M6Zn0.5(4\%) in Fig. 6, and the close connection of the hydrated gel products between the particles leads to an increase in the overall compactness and an increase in the strength of the macroscopic structure. This is due to the addition of water glass to form a bonded network structure, which increases the contact area and reaction time between $\mathrm{MgO}$ and phosphate and increases the possibility of generating hydrated gel structure products, thereby enhancing the compactness of the structure and alleviating the MKP dissolution tendency. At the same time, this behavior strengthens the cementation between the soil particles and gel, reducing the structural dispersion of the solidified soil, and reducing the dissolution probability of $\mathrm{Zn}^{2+}$. This test result is similar to Yang [25] and Shi [26] microscopic analysis of the effect mechanism of water glass water glass on MPC, indicating that under the joint action of acid rain and heavy metals, the addition of water glass can maintain the long-term properties and acid resistance of solidified heavy metal contaminated soil.
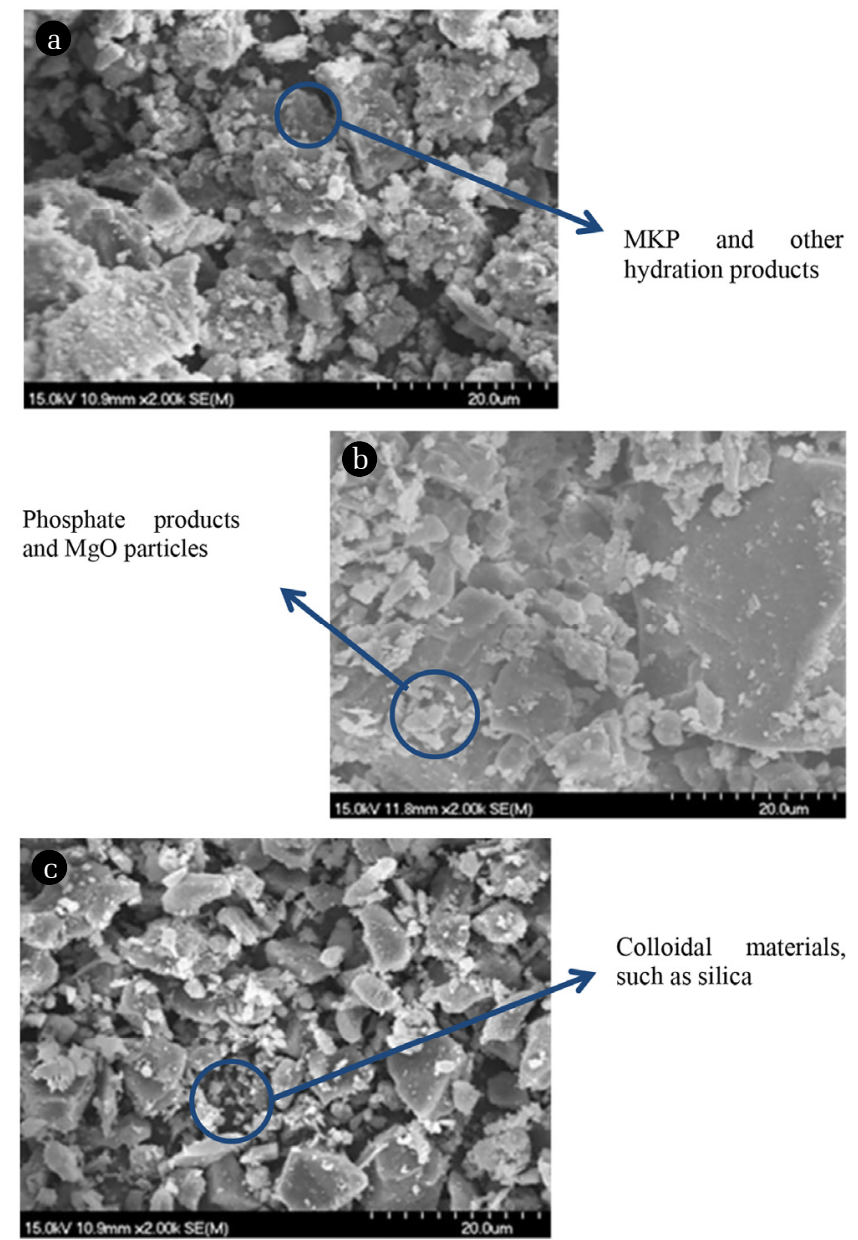

Fig. 7. SEM images of the semi-dynamic leached samples. (a) $\mathrm{M} 6 \mathrm{ZnO}(0 \%)$ $\mathrm{pH}=4$ (2,000 times), (b) M6Zn0.5(0\%), $\mathrm{pH}=4$ (2,000 times), (c) M6Zn0.5(4\%), $\mathrm{pH}=4$ (2,000 times).

\section{Conclusions}

In this paper, laboratory studies were carried out for zinc-contaminated soil to investigate the MPC solidification mechanism, the erosion mechanism of acid rain and the acid resistance after adding water glass. The following conclusions can be drawn: In an acidic environment, the effect of M4 solidified zinc contaminated soil is more affected by acid than M6; The addition of water glass enhances the bonding between the soil particles and the gel body. Thus reductions in both the structural dispersion of the solidified soil and the dissolution probability of $\mathrm{Zn}^{2+}$ can be observed; Comparing different water glass content, it is found that $4 \%$ water glass content can effectively improve the cement curing effect of heavy metal $\mathrm{Zn}$ in an acid rain environment. Therefore, water glass can be used as a good admixture for the solidification of heavy metal Zn by MPC in acid rain environment, and maintain the long-term properties and acid resistance of solidified heavy metal contaminated soil. 


\section{Acknowledgment}

This work was supported financially by the Provincial Fund-East China Institute Joint Fund / Key Project (LHZ19E090001) and National Natural Science Foundation of China (No.51778585). We thank Ding, Yaokun for his guidance on the test.

\section{Author Contributions}

Z.W. (Professor) provided the research ideas and thoughts. H.L.Z. (Ph.D. student) designed the experiment. And the experiment was mainly completed by H.J.Z. (ma.eng. student), X.H.W. (Ph.D. student), and B.P.W. (ma.eng. student). S.F.X. (Professor) summarized the experimental data and finished writing the experimental report.

\section{References}

1. Chen HY, Teng YG, Lu SJ, Wang YY, Wang JS. Contamination features and health risk of soil heavy metals in China. Sci. Total Environ. 2015;512:143-153.

2. Liu LW, Li W, Song WP, Guo MX. Remediation techniques for heavy metal-contaminated soils: Principles and applicability. Sci. Total Environ. 2018;633:206-219.

3. Vongdala N, Tran HD, Xuan TD, Teschke R, Khanh TD. Heavy Metal Accumulation in Water, Soil, and Plants of Municipal Solid Waste Landfill in Vientiane, Laos. Int. J. Env. Res. Pub. He. 2019;16(01):22.

4. Gowd SS, Reddy MR, Govil PK. Assessment of heavy metal contamination in soils at Jajmau (Kanpur) and Unnao industrial areas of the Ganga Plain, Uttar Pradesh, India. J. Hazard. Mater. 2010;174(01-03):113-121.

5. Wei X, Gao B, Wang P, Zhou HD, Lu J. Pollution characteristics and health risk assessment of heavy metals in street dusts from different functional areas in Beijing, China. Ecotox. Environ. Safe. 2015;112:186-192.

6. Garau M, Garau G, Diquattro S, Roggero PP, Castaldi P. Mobility, bioaccessibility and toxicity of potentially toxic elements in a contaminated soil treated with municipal solid waste compost. Ecotox. Environ. Safe. 2019;186:109766.

7. Zhao L, Xu YF, Hou H, Shangguan YX, Li YX. Source identification and health risk assessment of metals in urban soils around the Tanggu chemical industrial district, Tianjin, China. Sci. Total Environ. 2014;468:654-662.

8. Paria S, Yuet PK. Solidification-stabilization of organic and inorganic contaminants using portland cement: a literature review. Environ. Rev. 2006;14:217-255.

9. Wang F, Zhang YH, Shen ZT, Pan H, Xu J, Al-Tabbaa A. GMCs stabilized/solidified $\mathrm{Pb} / \mathrm{Zn}$ contaminated soil under different curing temperature: leachability and durability. Environ. Sci. Pollut. R. 2019;26(26):26963-26971.

10. Cubukcuoglu B, Ouki SK. Comparison of mechanical and leaching behaviours of pulverised fuel ash/low-grade magnesium oxide-cement blended stabilised/solidified baghouse dust. Eur. J. Environ. Civ. Eng. 2019;23(06):771-788.
11. Abu QH, Begday IV, Shkarlet KY, Harin KV, Bluzhina AS, Likhovid AA. Leachability of heavy metals from stabilized/solidified mine tailing in Russia. Eng. Res. 2019;07(03):62-75.

12. Lu HX, Wei F, Tang JC, Giesy JP. Leaching of metals from cement under simulated environmental conditions. Environ. Manage. 2016;169:319-327.

13. He YJ, Lai ZY, Yan T, et al. Effect of $\mathrm{Cd}^{2+}$ on early hydration process of magnesium phosphate cement and its leaching toxicity properties. Constr. Build Mater. 2019;209:32-40.

14. He X, Lai ZY, Yan T, et al. Hydration characteristics and microstructure of magnesium phosphate cement in presence of $\mathrm{Cu}^{2+}$. Constr. Build Mater. 2019;225: 234-242.

15. Wang P, Xue Q, Yang ZN, Li JS, Zhang TT, Huang Q. Factors Affecting the Leaching Behaviors of Magnesium Phosphate Cement-Stabilized/Solidified Pb-Contaminated Soil, Part II: Dosage and Curing Age. Environ. Prog. Sustain. 2017;36(05): 1351-1357.

16. Liu JJ, Zha FS, Xu L, Yang CB, Chu CF, Tan XH. Effect of chloride attack on strength and leaching properties of solidified/stabilized heavy metal contaminated soils. Eng. Geol. 2018; 246:28-35.

17. Fu SF, Lin SG. Geotechnical Problems of Polluted Soil. Eng. Investigation. 1989;(03):6-10. (In Chinese)

18. Du YJ, Wei ML, Reddy KR, Liu ZP, Jin F. Effect of acid rain $\mathrm{pH}$ on leaching behavior of cement stabilized lead-contaminated soil. J. Hazard. Mater. 2014;271:131-140.

19. Rao AJ, Pagilla KR, Wagh AS. Stabilization and solidification of metal-laden wastes by compaction and magnesium phosphate-based binder. J. Air Waste Manage. 2000;50(9):1623-1631.

20. Buj I, Torras J, Rovira M, Pablo J. Leaching behaviour of magnesium phosphate cements containing high quantities of heavy metals. J. Hazard. Mater. 2010;175(1-3):789-794.

21. Li JS, Xue Q, Wang P. Comparison of solidification/stabilization of lead contaminated soil between magnesia-phosphate cement and ordinary portland cement under the same dosage. Environ. Prog. Sustain. 2016;35(01):88-94.

22. Arora A, Singh B, Kaur P. Novel material i.e. magnesium phosphate cement (MPC) as repairing material in roads and buildings. Materials Today: Proceedings, 2019;17:70-76.

23. Xu SF, Wu XH, Cai YQ, Ding YK, Wang Z. Strength and Leaching Characteristics of Magnesium Phosphate Cement-Solidified Zinc- Contaminated Soil under the Effect of Acid Rain. Soil Sediment Contam. 2018;27(02):161-174.

24. Hu L. Research and Engineering Application of Sodium Water Glass High Temperature Resistant Adhesive, Guangzhou, South China University of Technology. 2011. (In Chinese)

25. Yang JM, Qian CX, Zhou QZ. Effect of water glass on properties of potassium magnesium phosphate cement. Building Materials. 2011;14(2):227-233. (In Chinese)

26. Shi CJ, Yang JM, Yang N, Chang Y. Effect of waterglass on water stability of potassium magnesium phosphate cement paste. Cement. Concrete. Comp. 2014;53:83-87.

27. Cuisinier O, Le Borgne T, Deneele D, Masrouri F. Quantification of the effects of nitrates, phosphates and chlorides on soil stabilization. Eng. Geol. 2011; 117(3-4):229-235.

28. Liao XY, Chong ZY, Yan XL. Urban Industrial Pollution Sites: New Issues in Environmental Remediation in China. Environ. 
Sci. 2011;32(2):784-794.

29. A.S.T.M. C1308-08. Standard method for accelerated leach test for diffusive release from solidified waste and a computer program to model diffusive, fractional leaching from cylindrical waste forms. ASTM International. 2009.

30. Wang JR, Ma BG, Li XG. The solidification and hydration products of magnesium phosphate cement with $\mathrm{Pb}^{2+}, \mathrm{Zn}^{2+}, \mathrm{Cu}^{2+}$. Funct. Mater. Lett. 2014;45(05):60-64.

31. Ding YK. Study on the solidification mechanism of magnesium phosphate cement to heavy metal contaminated soil in acid rain environment. Zhejiang University of Technology. 2015. (In Chinese).

32. Wang Z, Ding YK, Xu SF. Dissolution characteristics of zinc contaminated soil solidified with magnesium phosphate cement under acid rain environment. Geotech. Eng. 2017;39:698-704. (In Chinese)

33. Wagh AS, Singh D, Jeong S. Method of waste stabilization via chemically bonded phosphate ceramics. USA Patent, No. 5830815. 1998.

34. Qiao F, Chau CK, Li ZJ. Property evaluation of magnesium phosphate cement mortar as patch repair material. Constr. Build Mater. 2010;24(5):695-700.

35. Qiao F, Chau CK, Li ZJ. Microstructure of magnesium potassium phosphate cement. Constr. Build Mater. 2011;25(6):2911-2917.

36. Wang AJ, Fan XJ, Li JM, Chen D. Curing behavior and structure of magnesium phosphate chemically bonded ceramics with different $\mathrm{MgO}$ to $\mathrm{KH}_{2} \mathrm{PO}_{4}$ ratios. Int. J. Appl. Ceram Tec. 2014;12(06):1124-1130.

37. Lahalle H, Coumes CCD, Mesbah A, et al. Investigation of magne- sium phosphate cement hydration in diluted suspension and its retardation by boric acid. Cement. Concrete Res. 2016;87: 77-86.

38. Ma C, Chen B. Experimental study on the preparation and properties of a novel foamed concrete based on magnesium phosphate cement. Constr Build Mater. 2017;137(15):160-168.

39. Ding Z, Dong BQ, Xing F. Cementing mechanism of potassium phosphate based magnesium phosphate cement. Ceram. Int. 2012;38:6281-6288.

40. Xu BW, Lothenbach B, Leemann A, Winnefeld F. Reaction mechanism of magnesium potassium phosphate cement with high magnesium-to-phosphate ratiod. Cement. Concrete Res. 2018; 108:140-151.

41. Haque MA, Chen B. Research progresses on magnesium phosphate cement: A review. Constr. Build Mater. 2019;211(30): 885-898.

42. Jiao CS, Wang ZP, Zhang WJ. Promising inorganic adhesives. Chemistry and Adhesion. 1999;(04):202-203. (In Chinese)

43. Du YJ, Wei ML, Reddy KR, Jin F, Wu HL, Liu ZB. New phosphate-based binder for stabilization of soils contaminated with heavy metals: leaching, strength and microstructure characterization. Environ. Manage. 2014;146:179-188.

44. Lai ZY, Lai XC, Shi JB, Lu ZY. Effect of $\mathrm{Zn}^{2+}$ on the early hydration behavior of potassium phosphate based magnesium phosphate cement. Constr. Build Mater. 2016;129:70-78.

45. He YJ, Yan T, He X, et al. Effect of $\mathrm{Cd}^{2+}$ on early hydration process of magnesium phosphate cement and its leaching toxicity properties $\mathrm{Cd}^{2+}$. Constr. Build Mater. 2019;209:32-40. 